\title{
Correction
}

\section{Erratum: lemi and Busch, Moment-to-Moment Fluctuations in Neuronal Excitability Bias Subjective Perception Rather than Strategic Decision-Making (eNeuro May/June 2018, 5(3) e0430-17.2018 1-13 https://doi.org/10.1523/ENEURO.0430-17.2018)}

In the article "Moment-to-Moment Fluctuations in Neuronal Excitability Bias Subjective Perception Rather than Strategic Decision-Making," by Luca lemi and Niko A. Busch, which appeared as 0430-17.2018 in the May/June 2018 issue, some of the article text appeared incorrectly.

On page 3, in the second sentence under the heading "EEG recording and preprocessing," the text "Position Coordinates" should be omitted.

On page 5, "Signal dection theory (SDT)," should read "Signal detection theory (SDT)."

These errors do not affect the conclusions of the paper. The article has been corrected online. 